\title{
Comprehensive cancer control in the United States: progress and opportunity
}

\author{
Leslie S. Given · Karin Hohman • Madeline La Porta • \\ Lori Belle-Isle $\cdot$ Phyllis Rochester
}

Published online: 30 October 2010

(C) Springer Science+Business Media B.V. 2010

This Special Issue is a description of progress in the comprehensive cancer control (CCC) movement in the United States, since the first Special Issue on comprehensive cancer control was published in October 2005. Comprehensive cancer control as a concept and a way of addressing the cancer burden in the United States has evolved since 2005: additional CCC programs have been funded through the Centers for Disease Control and Prevention's National Comprehensive Cancer Control Program; CCC coalitions have expanded their partnerships and obtained additional resources to support the implementation of their CCC plans; many states, tribes and tribal organizations, territories and Pacific Island Jurisdictions have updated their CCC plans and refocused their priorities; additional organizations have joined a group of national partners to offer support and resources to $\mathrm{CCC}$ coalitions, and the body of evidence that CCC can make a positive impact on the burden of cancer in the United States is growing.

\footnotetext{
L. S. Given ( $\square)$

Strategic Health Concepts, Atlanta, GA, USA

e-mail: leslie@shconcepts.com

K. Hohman

Strategic Health Concepts, Arvada, CO, USA

M. La Porta

National Cancer Institute, Bethesda, MD, USA

L. Belle-Isle

American Cancer Society, Atlanta, GA, USA

P. Rochester

Centers for Disease Control and Prevention, Atlanta,

GA 30341-3717, USA
}

In this Special Issue, we present a series of papers that address several aspects of CCC that are of critical interest to the field of cancer control: sustaining partnerships; revising and implementing $\mathrm{CCC}$ plans; evaluating and measuring the impact of CCC efforts; supporting colorectal cancer screening through $\mathrm{CCC}$; implementing policy actions to support CCC efforts; establishing linkages between CCC coalitions and the research community; fostering local implementation of CCC plans and addressing disparities through CCC coalition efforts. Each paper highlights successes of national, state, tribal, territory and Pacific Island Jurisdiction CCC programs and coalitions that are data driven and based on sound evidence or a promising practice.

Comprehensive cancer control is a systematic approach for maximizing resources, reducing duplication of effort and focusing on evidence-based interventions across the continuum of cancer control. Yet, as this Special Issue shows, the true purpose and center of all these CCC efforts is people-individuals living better and longer lives in a community where their risk for cancer is lessened along with the burden of cancer on the community. The papers in this Special Issue articulate the continuing value of comprehensive cancer control and present opportunities for journal readers of all disciplines to become involved in the CCC movement.

Special Issue Editorial Workgroup Members

Leslie Given, MPA

Lori Belle-Isle, MPH

Karin Hohman, RN, MBA

Madeline La Porta, MS

Phyllis Rochester, $\mathrm{PhD}$ 